\title{
Individual and monitoring centre influences upon anticoagulation control of AF patients on warfarin: a longitudinal multi-centre UK-based study
}

Running title: Centre-based influences on anticoagulation

\section{Salah Abohelaika'; Hilary Wynne ${ }^{2}$; Peter Avery ${ }^{3}$; Brian Robinson ${ }^{4}$; Lisa Jones ${ }^{5}$; Campbell Tait ${ }^{6}$; Bradley Dickinson ${ }^{7}$; Julie Salisbury ${ }^{8}$; Joanna Nightingale $^{9}$; Louise Green $^{10}$; Farhad Kamali ${ }^{1}$}

1. Institute of Cellular Medicine, Newcastle University, Newcastle upon Tyne, UK

2. Older People's Medicine, Newcastle upon Tyne Hospitals, NHS Foundation Trust, UK

3. School of Mathematics and Statistics, Newcastle University, Newcastle upon Tyne, UK

4. Department of Haematology, Newcastle upon Tyne Hospitals, NHS Foundation Trust, UK

5. Blackpool Victoria Hospital, Blackpool Teaching Hospitals NHS Foundation Trust, UK

6. NHS Greater Glasgow and Clyde Anticoagulation Service, Glasgow, UK

7. Leeds Teaching Hospitals NHS Foundation Trust, UK

8. Mid Cheshire Hospitals NHS Foundation Trust, UK

9. East Kent Hospitals University NHS Foundation Trust, UK

10. Royal Shrewsbury Hospital Shrewsbury and Telford Hospital NHS Trust, UK

Corresponding Author: Professor Farhad Kamali, Institute of Cellular Medicine, Newcastle University, Newcastle upon Tyne Hospitals Foundation Trust, Newcastle upon Tyne, NE2 4HH. Fax: +44 1912225827 Email address: (farhad.kamali@ncl.ac.uk).

Tel no: +44 1912088043

This article has been accepted for publication and undergone full peer review but has not been through the copyediting, typesetting, pagination and proofreading process, which may lead to differences between this version and the Version of Record. Please cite this article as doi: 10.1111/ejh.13130

This article is protected by copyright. All rights reserved. 


\begin{abstract}
Objectives: Time within therapeutic INR range (TTR) predicts benefits/risk of warfarin therapy. Identification of individual- and centre-related factors that influence TTR, and addressing them to improve anticoagulation control, are important. This study examined the impact of individual and centre-related factors upon long-term anticoagulation control in atrial fibrillation patients in seven UK-based monitoring services.
\end{abstract}

Methods: Data between 2000 and 2014 on 25,270 patients (equating to 203,220 patient years) $[18,120(71.7 \%)$ in general practice, $2,348(9.3 \%)$ in hospital-based clinics and 4,802 (19.0\%) in domiciliary service] were analysed.

Results: TTR increased with increasing age, peaking around $77 \%$ at $70-75$ years, and then declined, was lower in females than males, and in dependent homemonitored patients than those attending clinic $(P<0.0001)$. TTR, number of dose changes and INR monitoring events, and the probability of TTR $\leq 65 \%$, differed across the centres $(P<0.0001)$.

Conclusions: Although all the participating centres ostensively followed a standard dosing algorithm, our results indicate that variations in practice do occur between different monitoring sites. We suggest feedback on TTR for individual monitoring sites gauged against the average values reported by others would empower the individual centres to improve quality outcomes of anticoagulation therapy by identifying and adjusting contributory factors within their management system.

Key words: warfarin, atrial fibrillation, anticoagulation, stroke, TTR 


\section{Introduction}

Trial data of patients with atrial fibrillation (AF) taking warfarin indicate that quality of warfarin use, as measured by average time in the standard target range (TTR) of 2.0-3.0 influences both risk of major bleeding and thromboembolic events (1). Similar benefits in terms of preventing stroke or systemic embolism have been noted both in patients treated with non-vitamin $\mathrm{K}$ antagonist oral anticoagulants (NOACs) and those treated with warfarin with high TTR (2), with no differences between the treatments in rates of thromboembolic or thrombotic events where, in warfarin treated patients, mean TTR was $70 \%$ (3). As a result of these findings interpolated TTR (4) has become a standard measure of quality of warfarin management. Unfortunately many vitamin $\mathrm{K}$ antagonist (VKA) treated patients do not achieve a TTR of $>70 \%$, with a meta-analysis of published data suggesting that patients spend an average of $61 \%, 25 \%$ and $14 \%$ of their time within, above and below range, respectively (5). This is important as patients with an individual TTR of less than $70 \%$, or high INR variability, have an increased rate of major bleeding or thromboembolism (6); those with a TTR of $>70 \%$ have a $79 \%$ reduced risk of stroke compared with those with $<30 \%$ TTR, and mortality rates are significantly lower in those with a TTR $>70 \%$ than those not achieving this (7). $57 \%$ of thrombotic events and $42 \%$ of haemorrhage events occur at an INR of $<2.0$ and $>3.0$ respectively (5). Factors influencing TTR are both individual based (ITTR) and centre based (CTTR), with iTTR significantly predicting risk of major haemorrhage, ischaemic stroke and all-cause mortality, and cTTR being a weak predictor of all-cause mortality (8). Identification of the influences upon these outcomes is important to ascertain which ones are modifiable and improvable. 
Patient factors known to predict poor INR control include age less than 60 years, female sex and having more than 2 co-morbidities, factors which have been included in the SAME-TT2R2 score aimed at aiding decision making between a NOAC and a VKA (9), heart failure (10) and severe chronic kidney disease (11). In an earlier longitudinal study of anticoagulation control we demonstrated a biphasic relationship with age, TTR peaking at 67 years, being poorer in females than in males, and in patients monitored at home due to dependency and immobility than in those attending monitoring clinic (12).

VKA monitoring setting influences TTR with patients managed in anticoagulation clinics and with adherence to a warfarin dosing algorithm having better control and outcomes than those managed in community settings $(8,13,14)$. Thus, for example, patients in North America spend significantly less time in the therapeutic range than those in Europe, where results are best in Sweden, then the United Kingdom (UK) (5), both of which have a similar anticoagulant management system. In the United States (US) however, only about one third of patients have access to an anticoagulant clinic (15), and other strategies which can improve TTR for some patients such as self-monitoring are less used (16).

We set out to investigate the impact of age, gender and differences between management systems (hospital, general practice and domiciliary) on anticoagulation control in seven UK-based centres to determine to what extent our earlier observations of age-related effects upon \%TTR were replicable elsewhere, and to examine any differences in centre-based TTRs which might be indicative of systembased differences in management which could potentially be addressed to enhance 
the quality of anticoagulation control, as many of the patient factors influencing TTR are fixed and may not be easily amenable to change by targeted interventions.

\section{Patients, materials and Methods}

The study involved audit of anonymised electronic data held by 7 centres across the UK using the DAWN computer dosing programme (version 6.10, Milnthorpe, Cumbria, UK) (17), and as such, the study was deemed not to require ethical approval. Patient inclusion criteria were to have AF, paroxysmal, persistent or valvular, anticoagulated for stroke and systemic embolism prevention and with a target INR of 2.0-3.0. Only these patients were selected in order to reduce bias related to different indications or target INR ranges. After excluding the data for the first six months of warfarin therapy, only those patients aged 40 years or older who were monitored for 5 consecutive years or more, and had 4 or more yearly INR measurements, without a change in monitoring setting were included in the final analysis. Data mining was facilitated by DAWN which allowed extraction of information on individual patients and their anticoagulation management setting, between 2000 and 2014, including a DAWN coded patient ID (in order to preserve patient anonymity for data analysis), age, sex, indication for anticoagulant therapy, target INR range, date commencing warfarin treatment and starting dose, duration of warfarin therapy, mean annual warfarin dose, annual number of INR monitoring events and warfarin dose changes. Data for mobile patients who attended either hospital or general practice based clinics, and for patients housebound by physical dependency or limited mobility who were monitored through the domiciliary service whereby trained staff visited them at their place of residence for venous or point of 
care INR checks, were audited. Information on co-morbidities and concurrent therapy, major bleeding or thromboembolism, was not available.

\section{Statistical Analysis}

The mean of the individual variables, including \% time within, below and above therapeutic INR range (TTR) established using the linear extrapolation (4), number of INR determinations and dose changes, and average warfarin dose was determined according to each year of age collectively for all centres and for each centre individually.

Examination of the data showed that INR control was less good in the youngest and oldest patients. As a result a polynomial model with age was fitted to the means to describe this effect and the way the covariates of setting and gender affected this model was examined. The number of INR measurements and the number of warfarin dose changes were transformed into their square roots to approach normality.

Since some data had a polynomial pattern, for later analysis quadratic, cubic, quartic and linear regression models were applied to examine the effect of age for all the variables tested.

Weighted analysis was used in all statistical calculations because of the large variation in sample sizes across age groups. Individual observations were also analysed using random effects to take account of the longitudinal nature of the data. This form of analysis was more complex due to the non-normal nature of the data. The same conclusions were obtained and so the analysis of means is presented 
here as the interpretation of the analysis is much more straightforward. The probability of a TTR $\leq 65 \%$ according to age was determined using binary logistic regression analysis. Quartic regression models were used to examine the effect of age on gender, monitoring centre, and monitoring setting. Data were analysed using Minitab statistical software (version 17.0) and R statistical package. Data are presented as mean \pm SD unless stated otherwise.

\section{Results}

Data belonging to $72,441 \mathrm{AF}$ patients (equating to 384,977 patient years) anticoagulated with warfarin for stroke and systemic embolism prevention with INR target of 2.0-3.0 in 7 different centres across 6 different regions in the UK were extracted from DAWN electronic database. A total of 25,270 patients $(203,220$ patient years) with 2,308,043 INR determinations and 664,717 warfarin dose changes were available for data analysis. For centres 2, 3, 6 and 7, patients were recorded as being monitored either at 'hospital',' GP', or 'home'. For centres 1 and 4, patients were monitored at either 'home' or 'GP', and for centre 5 at 'GP' only. The clinic monitoring system description and the number of patients monitored and their mean age at each of the individual centres according to setting are presented in Table 1 and Table 2, respectively.

\%TTR, time spent above and below target INR range were significantly associated with age ( $P<0.0001)$, (Fig 1). The \%TTR increased with increasing age, peaked to about $77 \%$ at $70-75$ years of age, and declined with increasing age thereafter. The time spent above target INR range was greater in older age, whereas the time below target INR range was greater in younger age. For the whole study population age 
accounted for $95 \%, 87 \%$, and $91 \%$ of the variability in mean TTR, time spent above and below target INR range, respectively.

Warfarin dose requirement fell with increasing age $(\mathrm{P}<0.0001$, quartic regression), with age accounting for $99.7 \%$ of the variability in dose requirement. Hospital and GP monitored patients were prescribed a significantly higher mean warfarin dose than those monitored at home for most ages, the reverse being true for age less than 55 $(\mathrm{P}<0.0001)$. For the whole population both the mean number of dose changes (as square root) $\left(P<0.0001, R^{2}=96 \%\right.$, quartic regression) and the mean number of INR monitoring events (as square root) $\left(P<0.0001, R^{2}=95 \%\right.$, cubic regression) were significantly related to age (Fig 2).

There was a highly significant difference in both the number of INR measurements (square root; $\mathrm{P}<0.0001, \mathrm{R}^{2}=90 \%$, cubic regression) and warfarin dose changes $\left(P<0.0001, R^{2}=93 \%\right.$, quartic regression) between the 7 study centres (Table 3 ). TTR was found to be highly significantly different between the seven centres $\left(P<0.0001, R^{2}=93 \%\right.$, quartic regression). Centre 5 had the highest TTR and probability of having a TTR $\geq 65 \%$ and centre 6 the lowest $(P<0.001)$, particularly for patients aged over 80 years. Percentage time above $\left(P<0.0001, R^{2}=91 \%\right.$, cubic regression) and below target INR range $\left(P<0.0001, R^{2}=82 \%\right.$, quartic regression) was highly significantly different between the seven centres; centre 5 had the lowest \%time above target INR range, and centre 3 the highest. Centres 5 and 7 had the two lowest \%time below target INR range; centre 6 had the highest, contributed to by warfarin doses which were significantly lower than those recorded at the other study centres $\left(P<0.0001, R^{2}=99 \%\right.$, quartic regression); (Fig 3). 
In females the mean TTR was marginally lower (by $1.12 \% ; P<0.0001$ ), and both the mean \%time below $(0.57 \%, \mathrm{P}<0.0001)$ and above target INR range $(0.53 \%$, $\mathrm{P}<0.0001)$ were marginally higher compared to males. Female patients had a marginally higher number of recorded INR checks $(P<0.0001)$. Warfarin doses for females were significantly lower than those for males $(P<0.0001)$, and they had more dose changes $(P<0.0001)$ than their male counterparts. In spite of this, females had a slightly higher probability of having a TTR $\leq 65 \%(P<0.0001$, quartic regression) compared to males, with centre 6 having the highest probability and centre 5 the lowest $(P<0.0001$, quartic regression).

The TTR of patients monitored at hospital and GP settings exceeded that of those monitored at home by $3.7 \%$ whereas, for the \%time above and below target INR range, patients monitored at home exceeded those monitored at hospital and GP by $1.6 \%$ and $2.1 \%$, respectively $(P<0.0001)$, but with a non-interacting effect with age. Patients monitored at home had a greater frequency of INR checks and warfarin dose changes (by 0.24 and 0.26 of squared root values, respectively) but,(with the exclusion of centres 5 and 6 as centre 5 has no home-monitored system in place and there was a small number of home-monitored patients at centre 6), nevertheless, had a markedly greater probability of having a TTR $\leq 65 \%$ compared to hospital and GP monitored patients; 10\% greater across most ages.

\section{Discussion}

In this study we were able to follow-up longitudinally 25,270 patients (amounting to 203,220 patient years of observation) across 7 different centres and establish that there is a consistent pattern of the effects of age and gender and dependency upon 
TTR, it peaking at around $70-75$ years, being lower in females than in males and in individuals requiring home monitoring than those attending clinic, whilst there are considerable differences between the centres in quality of anticoagulant control achieved. Achieving good anticoagulation control is important to optimising outcomes in AF patients taking warfarin, with risks of death, MI, major bleeding, stroke or systemic embolism being related to anticoagulation control (18). Using data from the ARISTOTLE, ROCKET AF and RELY trials of use of apixaban, rivaroxaban and dabigatran respectively, it has been estimated that, among non-valvular AF patients, each $10 \%$ increase in TTR in warfarin treated patients correlates with a $0.32 \%$ per year decrease in stroke/ systemic embolism rate, but it has no effect on major bleeding (19).

As noted in our previous single centre longitudinal study (12), we have confirmed a consistent curvilinear relationship between TTR and age across all the three monitoring settings (hospital, GP and domiciliary) in the 7 studied centres at 6 different geographical locations across the UK, with TTR peaking at age 71 . There was an inverse relationship between the number of INR checks and warfarin dose changes and age.

This curvilinear pattern was found for percentage of time both above and below range. The probability of having a TTR $\leq 65 \%$ increased over the age of 70 years, and control across centres was, as in our previous study (12), consistently worse in females than in males and in those monitored at home rather than clinic who had lower TTRs and spent more time both above and below their target range, in spite of greater frequency of INR checks and warfarin dose changes. Anticoagulated female 
AF patients show a slightly higher rate of ischaemic stroke than male patients (20), even after adjusting for TTR (21), suggesting the potential of a higher net clinical benefit of anticoagulant treatment in females, which is not being achieved. The greater risk of ischaemic stroke in women, in part related to females spending more time outside and below the therapeutic range than men $(9,22)$, suggests that they might benefit from a more aggressive VKA management, or anticoagulation with a NOAC, as these drugs have similar efficacy and bleeding risk in women and men (23).

The variability of cTTR is remarkable: a meta-analysis reported a range from $40 \%$ to $78 \%$ in US-based primary studies (24) and even in randomised controlled trials variability ranged from $44 \%$ to $77 \%(25)$. This is important as the benefit from the VKA oral anticoagulants is dependent upon TTR. In AF patients a $10 \%$ increase in time out of the therapeutic range is associated with an increase in the odds ratio of ischaemic stroke of $1.10, \mathrm{P}=0.006(26)$, and a population-average model predicted that a minimum TTR of $58 \%$ would be needed to be confident that patients would benefit from treatment (1). NOACs show a greater relative reduction in major bleeding, mainly driven by a reduction in haemorrhagic stroke compared to warfarin therapy when cTTR is $<66 \%$ whereas the benefits of NOACs over warfarin become less apparent when cTTR is $\geq 66 \%$ (27). As warfarin will continue to be used for many AF patients including those with rheumatic valvular disease, prosthetic heart valves or those with severe kidney disease, it is important to identify features of management which achieve excellence in anticoagulant control for sharing and adoption by currently less successful anticoagulation monitoring centres as achieving even a small percentage improvement in TTR would be of benefit to a 
large absolute number, given the estimated prevalence of $\mathrm{AF}$ in the general population of approximately $1 \% ; 2.2$ million people in the U.S. and 4.5 million in the European Union (28).

Variation in dose adjustment practice between each centre has been associated with cTTR, as well as differences in mean target INR levels (29). In our study we controlled for the latter by selecting data only from patients with a target range of 2.03.0. Other influences are participation in external assessment of therapy quality (30). Internal quality check was performed daily and external quality assurance undertaken monthly through National External Quality Assessment Service (NEQAS), Sheffield, UK at all the participating anticoagulation centres.

Important influences upon cTTR are that patients managed in a community setting have poorer control of anticoagulation when compared to those managed in an anticoagulant clinic or a RCT setting (5). Dose adjustments by clinicians, based upon experience, tend to under-dose patients whereas adherence to warfarin dosing algorithms is effective in improving anticoagulation control $(31,32)$. In the RELY study the degree of adherence accounted for $87 \%$ of the variation between participating centres and $55 \%$ of the between-country variation in TTR (25). Each $10 \%$ increase in the consistent use of dosing algorithm by centre independently predicted a $6.12 \%$ increase in TTR and an $8 \%$ decrease in the rate of the composite clinical outcome (25). Varying degrees of non-adherence to clinical guidelines is expected; in one study of USA veterans, none of the 5 sites studied were particularly adherent, with consistent patterns of concordant and discordant management in terms of dose changes and follow-up intervals being noted (33). Although all the 
participating centres in our study were ostensively following a standard warfarin dosing algorithm, variation in dose adjustment practice across the 7 centres must account for some of the observed differences in the study results between centres. As systems employing algorithm-based dosing and promoting adherence to them could improve clinical outcomes on a global scale, feedback to centres to improve patient outcomes by practising in a more guideline concordant manner is recommended. Anticoagulation management can be effectively carried out by a range of staff members; indeed there is strong evidence that community management utilising computer assisted dose adjustment can improve when led by pharmacists rather than primary care general practitioners; TTR improving from $71.4 \%$ to $84.1 \%$ in one New Zealand based study in spite of no increase in point of care INR testing (34). The $80 \%$ adherence to the algorithm by pharmacists compared to the $70 \%$ adherence by doctors was the most important factor influencing TTR rather than the specific details of the algorithm. Poorer control achieved by doctors compared to pharmacists (TTR $67.4 \%$ vs. $75.1 \%$ ) in another study was related to poorer adherence to computer dosing recommendations by doctors, with doctors over-riding the algorithm up to $50 \%$ of the time when INR was below range and tending to under-dose patients, mistakenly believing their own dose adjustments were better than the computer programme which had been developed using large amounts of patient data (35). Although this perhaps reflects inherent concern about the risk of bleeding in poorly controlled patients it will have achieved poorer outcomes as a meta-analysis has shown that a $6.9 \%$ improvement in TTR may reduce major haemorrhage by one event per hundred patient years of treatment (36). Centre 6 in our study, which used the lowest doses and had the highest \%TTR below range and the highest probability of TTR $<65 \%$, with comparable mean 
number of INR monitoring events and dose changes per patient per year to other centres (Table 2), had a larger number of individuals making dosing decisions, implicating these factors in poorer anticoagulation control. Dosage advice was not through a small number of anticoagulant clinic employed pharmacists, nurses or biomedical scientists, but was spread among anticoagulant nurses, practice nurses and community pharmacists, reducing the consistency of advice given. For centres 5 and 7, where TTRs were highest, dosing decisions were by anticoagulant nurses supported by consultant haematologist or pharmacists. That patients in our cohorts were more likely to be below therapeutic INR range and at increased risk of thrombosis, as compared to being above the range and at increased risk of bleeding, is consistent with pooled analysis of atrial fibrillation studies performed worldwide (5).

Anticoagulation control (TTR) could be improved if staff, whatever their grade, exhibited closer adherence to a rigorous protocol, including contacting non-attenders as part of their management process. Whilst feedback of a report contrasting their cTTR with the average cTTR of other participants may lead to centres taking steps to improving their quality, none of our centres was regularly provided with such feedback. We suggest that correcting this might be helpful, both to the centre to improve anticoagulation control overall and also to give each patient and his or her clinician knowledge of the individual's TTR over the previous 6 month period of VKA therapy to facilitate ongoing informed decision making about the choice of most appropriate oral anticoagulant. As whilst nearly $60 \%$ of AF patients on warfarin therapy with a TTR $\geq 70 \%$ will maintain this over the next 6 months, for a substantial minority TTR will deteriorate; the UK National Institute for Health and Care Excellence (NICE) recommends reassessment of anticoagulation for people with a 
TTR $<65 \%$ over a maintenance period of at least 6 months (37), and indeed for all patients this is important, particularly as patient features have been shown to be poor predictors of TTR variability (10).

Whilst INR monitoring intervals and to a lesser extent quality of laboratory INR measurement explained about $63.5 \%$ of the total TTR variability among Italian Federation of Anticoagulant Clinics (30), we noted more frequent testing and dosing changes in older and home-monitored patients who nevertheless had a lower \%TTR. This suggests that poorer anticoagulation control is related to patient factors such as dependency which cannot be completely adjusted for by monitoring and dosing decisions.

Limitations are that the study relied on self-reported centre characteristics to evaluate their association with centre TTR and this may have introduced information bias. Also, we did not measure variations in warfarin adjustment practice between centres, which is known to account for considerable cTTR variation and occurs even in the study situation (25) where mean percentage of algorithm-consistent warfarin dose changes ranged from only $55 \%$ in east Asia to $68 \%$ in north Europe and shows a strong positive association between the use of algorithm dose adjustments and TTR. Furthermore, we were unable to assess the extent to which differences in levels of co-morbidities and concurrent drug therapy were contributing to differences noted between centres, as data on these covariates were unavailable through the DAWN programme. This is regrettable as, although confounders are not fully elucidated, patient-level characteristics are known to contribute to variability in TTR. Of the 42 variables noted to have some influence upon TTR, the 6 clinical variables 
of pneumonia, renal dysfunction, prior bleeding, hospitalisation, pain medication and antibiotic use were particular confounders, but lack of a dedicated anticoagulation service with a structured approach to warfarin management was found to be the strongest predictor of poor TTR (38). In contrast, whilst comorbidities, medications, hospitalisations and ethnicity were shown in a study of 100 Veterans' Health Administration sites to account for $13.3 \%$ of the variability in TTR, site-level variability explained only $2.9 \%(39)$.

In conclusion, the results of this study of 7 UK monitoring centres are consistent with those of our previous study in 1 centre (12) in demonstrating that anticoagulation control shows a biphasic relationship with age, and is influenced by gender and dependency. More importantly in terms of potential for modification, it demonstrates differences in anticoagulation control between centres related to variations in practice. Feeding back TTR information to individual monitoring sites through peer review, such as, in the UK, the NEQAS for blood coagulation, the international External Quality Assessment (EQA) programme which provides assessment, education and support for centres performing tests of haemostasis and thrombosis through expert help, publications and scientific meetings, or through national training or clinical governance bodies under umbrella organisations such as, in the UK, the Royal College of Pathologists, so that they can gauge their performance against that of other services, has the potential to empower individual centres to identify and adjust contributory factors within their system, including adherence to algorithmic dosing protocol, with the aim of improving the delivery and quality outcomes of oral anticoagulation with warfarin. 


\section{Acknowledgements}

We would like to thank DAWN AC for their help with accessing and extracting data from the electronic databases held at the individual participating centres.

\section{Competing Interests}

All authors have completed the Unified Competing Interest form at http://www.icmje.org/coi_disclosur e.pdf (available on request from the corresponding author).

\section{Authorship Contributions}

SA, HW, PA and FK contributed to the study design. SA refined the database. Both SA and PA undertook statistical analysis of the data. SA, HW, PA and FK drafted the manuscript. All authors scrutinised and contributed to the redrafting of the manuscript.

\section{References}

1. Connolly SJ, Pogue J, Eikelboom J, Flaker G, Commerford P, Franzosi MG, Healey JS, Yusuf S. Benefit of oral anticoagulant over antiplatelet therapy in atrial fibrillation depends on the quality of international normalized ratio control achieved by centers and countries as measured by time in therapeutic range. Circulation. 2008; 118(20): 2029-37.

2. Wallentin L, Yusuf S, Ezekowitz MD, Alings M, Flather M, Franzosi MG, Pais P, Dans A, Eikelboom J, Oldgren J, Pogue J, Reilly PA, Yang S, Connolly SJ. Efficacy and safety of dabigatran compared with warfarin at different levels of international normalised ratio control for stroke prevention in atrial fibrillation: an analysis of the RE-LY trial. Lancet. 2010; 376(9745): 975-83.

3. Sjogren V, Bystrom B, Renlund H, Svensson PJ, Oldgren J, Norrving B, 
Sjalander A. Non-vitamin K oral anticoagulants are non-inferior for stroke prevention but cause fewer major bleedings than well-managed warfarin: A retrospective register study. PloS one. 2017; 12(7): e0181000.

4. Rosendaal FR, Cannegieter SC, van der Meer FJ, Briet E. A method to determine the optimal intensity of oral anticoagulant therapy. Thrombosis and haemostasis. 1993; 69(3): 236-9.

5. Mearns ES, Kohn CG, Song JS, Hawthorne J, Meng J, White CM, Raut MK, Schein JR, Coleman CI. Meta-analysis to assess the quality of international normalized ratio control and associated outcomes in venous thromboembolism patients. Thromb Res. 2014; 134(2): 310-9.

6. Bjorck F, Renlund H, Lip GY, Wester P, Svensson PJ, Sjalander A. Outcomes in a Warfarin-Treated Population With Atrial Fibrillation. JAMA Cardiol. 2016; 1(2): 172-80.

7. Gallagher AM, Setakis E, Plumb JM, Clemens A, van Staa TP. Risks of stroke and mortality associated with suboptimal anticoagulation in atrial fibrillation patients. Thrombosis and haemostasis. 2011; 106(5): 968-77.

8. Cancino RS, Hylek EM, Reisman JI, Rose AJ. Comparing patient-level and site-level anticoagulation control as predictors of adverse events. Thromb Res. 2014; 133(4): 652-6.

9. Apostolakis S, Sullivan RM, Olshansky B, Lip GY. Factors affecting quality of anticoagulation control among patients with atrial fibrillation on warfarin: the SAMeTT(2)R(2) score. Chest. 2013; 144(5): 1555-63.

10. Dallalzadeh LO, Go AS, Chang Y, Borowsky LH, Fang MC, Singer DE. Stability of High-Quality Warfarin Anticoagulation in a Community-Based Atrial Fibrillation Cohort: The Anticoagulation and Risk Factors in Atrial Fibrillation (ATRIA) Study. J Am Heart Assoc. 2016; 5(7).

11. Szummer K, Gasparini A, Eliasson S, Arnlov J, Qureshi AR, Barany P, Evans M, Friberg L, Carrero JJ. Time in Therapeutic Range and Outcomes After Warfarin Initiation in Newly Diagnosed Atrial Fibrillation Patients With Renal Dysfunction. J Am Heart Assoc. 2017; 6(3).

12. Abohelaika S, Wynne H, Avery P, Robinson B, Kesteven P, Kamali F. Impact of age on long-term anticoagulation and how gender and monitoring setting affect it: implications for decision making and patient management. British journal of clinical pharmacology. 2016; 82(4): 1076-83. 
13. Chiquette E, Amato MG, Bussey HI. Comparison of an anticoagulation clinic with usual medical care: anticoagulation control, patient outcomes, and health care costs. Arch Intern Med. 1998; 158(15): 1641-7.

14. Witt DM, Sadler MA, Shanahan RL, Mazzoli G, Tillman DJ. Effect of a centralized clinical pharmacy anticoagulation service on the outcomes of anticoagulation therapy. Chest. 2005; 127(5): 1515-22.

15. Nutescu EA, Bathija S, Sharp LK, Gerber BS, Schumock GT, Fitzgibbon ML. Anticoagulation patient self-monitoring in the United States: considerations for clinical practice adoption. Pharmacotherapy. 2011; 31(12): 1161-74.

16. Matchar DB, Jacobson A, Dolor R, Edson R, Uyeda L, Phibbs CS, Vertrees JE, Shih MC, Holodniy M, Lavori P, Committee TE, Site I. Effect of home testing of international normalized ratio on clinical events. N Engl J Med. 2010; 363(17): 160820.

17. 4S Information Systems Ltd TS, Milnthorpe, Cumbria, LA7 7QJ.

18. White HD, Gruber M, Feyzi J, Kaatz S, Tse HF, Husted S, Albers GW. Comparison of outcomes among patients randomized to warfarin therapy according to anticoagulant control: results from SPORTIF III and V. Arch Intern Med. 2007; 167(3): 239-45.

19. Amin A, Deitelzweig S, Jing Y, Makenbaeva D, Wiederkehr D, Lin J, Graham J. Estimation of the impact of warfarin's time-in-therapeutic range on stroke and major bleeding rates and its influence on the medical cost avoidance associated with novel oral anticoagulant use-learnings from ARISTOTLE, ROCKET-AF, and RE-LY trials. J Thromb Thrombolysis. 2014; 38(2): 150-9.

20. Pancholy SB, Sharma PS, Pancholy DS, Patel TM, Callans DJ, Marchlinski FE. Meta-analysis of gender differences in residual stroke risk and major bleeding in patients with nonvalvular atrial fibrillation treated with oral anticoagulants. Am J Cardiol. 2014; 113(3): 485-90.

21. Sullivan RM, Zhang J, Zamba G, Lip GY, Olshansky B. Relation of genderspecific risk of ischemic stroke in patients with atrial fibrillation to differences in warfarin anticoagulation control (from AFFIRM). Am J Cardiol. 2012; 110(12): 1799802.

22. Hylek EM. Vitamin $\mathrm{K}$ antagonists and time in the therapeutic range: implications, challenges, and strategies for improvement. J Thromb Thrombolysis. 2013; 35(3): 333-5. 
23. Ko D, Rahman F, Martins MA, Hylek EM, Ellinor PT, Schnabel RB, Benjamin EJ, Christophersen IE. Atrial fibrillation in women: treatment. Nat Rev Cardiol. 2017; 14(2): 113-24.

24. Cios DA, Baker WL, Sander SD, Phung OJ, Coleman Cl. Evaluating the impact of study-level factors on warfarin control in U.S.-based primary studies: a meta-analysis. Am J Health Syst Pharm. 2009; 66(10): 916-25.

25. Van Spall HG, Wallentin L, Yusuf S, Eikelboom JW, Nieuwlaat R, Yang S, Kabali C, Reilly PA, Ezekowitz MD, Connolly SJ. Variation in warfarin dose adjustment practice is responsible for differences in the quality of anticoagulation control between centers and countries: an analysis of patients receiving warfarin in the randomized evaluation of long-term anticoagulation therapy (RE-LY) trial. Circulation. 2012; 126(19): 2309-16.

26. Jones M, McEwan P, Morgan CL, Peters JR, Goodfellow J, Currie CJ. Evaluation of the pattern of treatment, level of anticoagulation control, and outcome of treatment with warfarin in patients with non-valvar atrial fibrillation: a record linkage study in a large British population. Heart. 2005; 91(4): 472-7.

27. Ruff CT, Giugliano RP, Braunwald E, Hoffman EB, Deenadayalu N, Ezekowitz MD, Camm AJ, Weitz JI, Lewis BS, Parkhomenko A, Yamashita T, Antman EM. Comparison of the efficacy and safety of new oral anticoagulants with warfarin in patients with atrial fibrillation: a meta-analysis of randomised trials. Lancet. 2014; 383(9921): 955-62.

28. European Heart Rhythm A, Heart Rhythm S, Fuster V, Ryden LE, Cannom DS, Crijns HJ, Curtis AB, Ellenbogen KA, Halperin JL, Le Heuzey JY, Kay GN, Lowe JE, Olsson SB, Prystowsky EN, Tamargo JL, Wann S, Smith SC, Jr., Jacobs AK, Adams CD, Anderson JL, Antman EM, Hunt SA, Nishimura R, Ornato JP, Page RL, Riegel B, Priori SG, Blanc JJ, Budaj A, Camm AJ, Dean V, Deckers JW, Despres C, Dickstein K, Lekakis J, McGregor K, Metra M, Morais J, Osterspey A, Zamorano JL, American College of C, American Heart Association Task Force on Practice G, European Society of Cardiology Committee for Practice G, Writing Committee to Revise the Guidelines for the Management of Patients With Atrial F. ACC/AHA/ESC 2006 guidelines for the management of patients with atrial fibrillation--executive summary: a report of the American College of Cardiology/American Heart Association Task Force on Practice Guidelines and the European Society of Cardiology Committee for Practice Guidelines (Writing Committee to Revise the 
2001 Guidelines for the Management of Patients With Atrial Fibrillation). J Am Coll Cardiol. 2006; 48(4): 854-906.

29. Rose AJ, Berlowitz DR, Miller DR, Hylek EM, Ozonoff A, Zhao S, Reisman JI, Ash AS. INR targets and site-level anticoagulation control: results from the Veterans AffaiRs Study to Improve Anticoagulation (VARIA). J Thromb Haemost. 2012; 10(4): 590-5.

30. Tosetto A, Manotti C, Marongiu F, Italian Federation of Anticoagulation Clinics clinical quality study g. Center-Related Determinants of VKA Anticoagulation Quality: A Prospective, Multicenter Evaluation. PLoS One. 2015; 10(12): e0144314.

31. Poller L, Wright D, Rowlands M. Prospective comparative study of computer programs used for management of warfarin. J Clin Pathol. 1993; 46(4): 299-303.

32. Kim YK, Nieuwlaat R, Connolly SJ, Schulman S, Meijer K, Raju N, Kaatz S, Eikelboom JW. Effect of a simple two-step warfarin dosing algorithm on anticoagulant control as measured by time in therapeutic range: a pilot study. $\mathrm{J}$ Thromb Haemost. 2010; 8(1): 101-6.

33. Kim B, Shaikh OA, Rose AJ. Examining Warfarin Dosing Decisions to Improve Anticoagulation Management. Journal of Pharmacy Technology. 2014; 30(5): 168-74.

34. Harrison J, Shaw JP, Harrison JE. Anticoagulation management by community pharmacists in New Zealand: an evaluation of a collaborative model in primary care. Int J Pharm Pract. 2015; 23(3): 173-81.

35. Harper P, Harper J, Hill C. An audit of anticoagulant management to assess anticoagulant control using decision support software. BMJ Open. 2014; 4(9): e005864.

36. Wan Y, Heneghan C, Perera R, Roberts N, Hollowell J, Glasziou P, Bankhead $\mathrm{C}, \mathrm{Xu}$ Y. Anticoagulation control and prediction of adverse events in patients with atrial fibrillation: a systematic review. Circ Cardiovasc Qual Outcomes. 2008; 1(2): 84-91.

37. National Institute for Health and Clinical Excellence. Atrial fibrillation. [Web page] 2015 Jul 2015 [cited Access date: 16/05/2016]; Available from: http://nice.org.uk/guidance/qs93

38. Lin KJ, Singer DE, Glynn RJ, Blackley S, Zhou L, Liu J, Dube G, Oertel LB, Schneeweiss S. Prediction Score for Anticoagulation Control Quality Among Older Adults. J Am Heart Assoc. 2017; 6(10). 
39. Rose AJ, Hylek EM, Berlowitz DR, Ash AS, Reisman JI, Ozonoff A. Prompt repeat testing after out-of-range INR values: a quality indicator for anticoagulation care. Circ Cardiovasc Qual Outcomes. 2011; 4(3): 276-82.

Table 1: System description for all participating centres

\begin{tabular}{|c|c|c|c|}
\hline & INR testing & Dosage Advice & Notes \\
\hline Centre 1 & $\begin{array}{l}\text { Point of care using Roche } \\
\text { Coaguchek pro devices }\end{array}$ & $\begin{array}{l}\text { Biomedical } \\
\text { scientists or } \\
\text { nurses }\end{array}$ & $\begin{array}{l}\text { Highest INR measurements } \\
\text { Highest dose changes }\end{array}$ \\
\hline Centre 2 & $\begin{array}{l}\text { Real time INR using } \\
\text { capillary method on KC1 } \\
\text { (Hart biological } \\
\text { machines/reagents/thromb } \\
\text { oplastin) }\end{array}$ & $\begin{array}{l}\text { Anticoagulant } \\
\text { nurse } \\
\text { practitioner }\end{array}$ & Education Programme \\
\hline Centre 3 & $\begin{array}{l}\text { Real time capillary method } \\
\text { Some self-monitoring }\end{array}$ & $\begin{array}{l}\text { Biomedical } \\
\text { scientists, } \\
\text { nurses, clinical } \\
\text { pharmacists, } \\
\text { pharmacy } \\
\text { technicians }\end{array}$ & Greatest time above range \\
\hline Centre 4 & $\begin{array}{l}\text { Self-monitoring } \\
\text { (Coaguchek Roche) }\end{array}$ & & \\
\hline Centre 5: & $\begin{array}{l}\text { Venous bloods-posted } \\
\text { dose advice } 100 \text { patients } \\
\text { self-monitor - telephoned } \\
\text { dose advice (Roche } \\
\text { Coaguchek) }\end{array}$ & $\begin{array}{l}\text { Anticoagulant } \\
\text { nurses } \\
\text { Consultant } \\
\text { Haematologist }\end{array}$ & $\begin{array}{l}\text { Highest TTR } \\
\text { Lowest time above range } \\
\text { Lowest time below range } \\
\text { Lowest TTR probability } \leq 65 \%\end{array}$ \\
\hline Centre 6: & $\begin{array}{l}\text { Capillary generated INR } \\
\text { using thrombotrak } \\
\text { coagulometers (Hart } \\
\text { biological } \\
\text { reagents/thromboplastin) } \\
\text { or Roche Coaguchek Pro } \\
\text { INR monitor } \\
\text { Some self-monitoring } \\
\text { Domiciliary service } \\
\text { Venous INR: } \\
\text { Community service: Roche } \\
\text { Coaguchek Pro }\end{array}$ & $\begin{array}{l}\text { Anticoagulant } \\
\text { nurses } \\
\text { Practice nurses } \\
\text { Community } \\
\text { pharmacist }\end{array}$ & $\begin{array}{l}\text { Lowest TTR } \\
\text { Highest time below range } \\
\text { Lowest doses prescribed } \\
\text { Highest TTR probability } \leq 65 \%\end{array}$ \\
\hline Centre 7: & $\begin{array}{l}\text { Capillary INR method on } \\
\text { KCI machines except for } \\
\text { domiciliary patients who } \\
\text { used venous INR } \\
\text { (Instrument Laboratories } \\
\text { machine and reagents) IL } \\
\text { (UK)Ltd }\end{array}$ & Pharmacist & $\begin{array}{l}\text { Education Programme } \\
\text { Lowest time below range }\end{array}$ \\
\hline
\end{tabular}

This article is protected by copyright. All rights reserved. 
Table 2: Number of patients monitored at each centre, and age (mean \pm SD) according to setting and gender

\begin{tabular}{|c|c|c|c|c|c|}
\hline \multirow[b]{2}{*}{ Centre } & & \multicolumn{3}{|c|}{ Category } & \multirow[b]{2}{*}{ Total } \\
\hline & & Domiciliary & GP & Hospital & \\
\hline \multirow{3}{*}{ 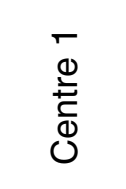 } & Males & 292 & 997 & & 1,289 \\
\hline & Females & 367 & 614 & & 981 \\
\hline & Total & 659 & 1,611 & & 2,270 \\
\hline \multirow{3}{*}{ 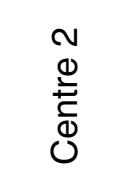 } & Males & 697 & 2,715 & 536 & 3,948 \\
\hline & Females & 909 & 1,968 & 327 & 3,204 \\
\hline & Total & 1,606 & 4,683 & 863 & 7,152 \\
\hline \multirow{3}{*}{ 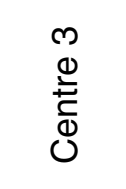 } & Males & 429 & 2,084 & 58 & 2,571 \\
\hline & Females & 567 & 1,343 & 63 & 1,973 \\
\hline & Total & 996 & 3,427 & 121 & 4,544 \\
\hline \multirow{3}{*}{ 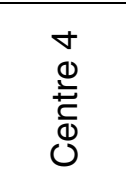 } & Males & 363 & 2,184 & & 2,547 \\
\hline & Females & 505 & 1,331 & & 1,836 \\
\hline & Total & 868 & 3,515 & & 4,383 \\
\hline \multirow{3}{*}{ 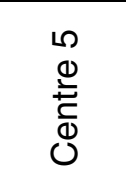 } & Males & & 1,794 & & 1,794 \\
\hline & Females & & 1,258 & & 1,258 \\
\hline & Total & & 3,052 & & 3,052 \\
\hline \multirow{3}{*}{ 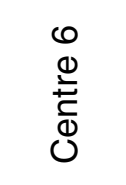 } & Males & 5 & 430 & 476 & 911 \\
\hline & Females & 8 & 257 & 397 & 662 \\
\hline & Total & 13 & 687 & 873 & 1,573 \\
\hline \multirow{3}{*}{ 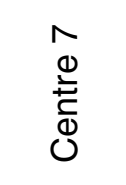 } & Males & 255 & 623 & 299 & 1,177 \\
\hline & Females & 360 & 322 & 186 & 868 \\
\hline & Total & 615 & 945 & 485 & 2,045 \\
\hline \multirow{6}{*}{$\begin{array}{l}\bar{\pi} \\
\stackrel{0}{0}\end{array}$} & Males & 2,041 & 10,827 & 1,369 & 14,237 \\
\hline & Age & & & & $71 \pm 9$ \\
\hline & Females & 2,716 & 7,093 & 973 & 10,782 \\
\hline & Age & & & & $75 \pm 8$ \\
\hline & Total & 4,757 & 17,920 & 2,342 & 25,019 \\
\hline & Age & $77 \pm 7$ & $71 \pm 9$ & $72 \pm 10$ & \\
\hline
\end{tabular}

N.B. Information about sex was not available for 251 patients 
Table 3: Mean number of INR checks and warfarin dose changes per patient per year in the individual centres

\begin{tabular}{|c|c|c|c|c|c|c|c|}
\hline Centre & Setting & $\begin{array}{c}\text { Total } \\
\text { number } \\
\text { of } \\
\text { patients }\end{array}$ & $\begin{array}{c}\text { Total } \\
\text { number } \\
\text { of } \\
\text { patients } \\
\text { years }\end{array}$ & $\begin{array}{c}\text { Mean } \\
\text { INR/patient } \\
\text { /year }\end{array}$ & $\begin{array}{c}\text { Mean } \\
\text { INR/patient } \\
\text { /year } \\
95 \% \mathrm{Cl}\end{array}$ & $\begin{array}{l}\text { Mean dose } \\
\text { change/ } \\
\text { patient/year }\end{array}$ & $\begin{array}{c}\text { Mean dose } \\
\text { change/ } \\
\text { patient/ year } \\
95 \% \mathrm{Cl}\end{array}$ \\
\hline \multirow{3}{*}{1} & Home & 696 & 5,971 & $14.6^{*}$ & $(14.3,14.9)$ & $4.9^{*}$ & $(4.7,5.1)$ \\
\hline & GP & 1,747 & 14,831 & $12.3^{*}$ & $(12.1,12.4)$ & $3.5^{*}$ & $(3.4,3.6)$ \\
\hline & Total & 2,443 & 20,802 & 12.9 & $(12.7,13.1)$ & 3.9 & $(3.8,4.0)$ \\
\hline \multirow{4}{*}{2} & Home & 1,608 & 12,456 & 12.7 & $(12.5,12.9)$ & 3.4 & $(3.3,3.5)$ \\
\hline & GP & 4,695 & 36,161 & 10.9 & $(10.8,11.0)$ & 2.4 & $(2.3,2.4)$ \\
\hline & Hospital & 864 & 6,492 & 11.4 & $(11.2,11.7)$ & 2.6 & $(2.5,2.7)$ \\
\hline & Total & 7,167 & 55,109 & 11.3 & $(11.3,11.4)$ & 2.6 & $(2.6,2.7)$ \\
\hline \multirow{4}{*}{3} & Home & 1,002 & 8,198 & 11.1 & $(10.9,11.3)$ & 3.3 & $(3.2,3.4)$ \\
\hline & GP & 3,443 & 29,587 & 10.4 & $(10.3,10.5)$ & 2.7 & $(2.6,2.7)$ \\
\hline & Hospital & 125 & 846 & 11.7 & $(11.1,12.3)$ & 3.3 & $(2.9,3.6)$ \\
\hline & Total & 4,570 & 38,631 & 10.6 & $(10.5,10.7)$ & 2.8 & $(2.8,2.9)$ \\
\hline \multirow{3}{*}{4} & Home & 868 & 7,369 & 13.4 & $(13.1,13.7)$ & 4.5 & $(4.4,4.7)$ \\
\hline & GP & 3,532 & 29,405 & 11.0 & $(10.9,11.1)$ & 3.0 & $(2.9,3.1)$ \\
\hline & Total & 4,400 & 36,774 & 11.5 & $(11.3,11.6)$ & 3.3 & $(3.2,3.3)$ \\
\hline 5 & GP & 3,065 & 24,207 & 11.2 & $(11.2,11.3)$ & 3.0 & $(3.0,3.1)$ \\
\hline \multirow{4}{*}{6} & Home & 13 & 88 & 11.0 & $(9.7,12.5)$ & 3.4 & $(2.7,4.1)$ \\
\hline & GP & 693 & 4,771 & 9.6 & $(9.4,9.9)$ & 2.4 & $(2.3,2.6)$ \\
\hline & Hospital & 874 & 6,350 & $12.1 \neq$ & $(11.8,12.5)$ & $3.7 \neq$ & $(3.5,3.9)$ \\
\hline & Total & 1,580 & 11,209 & 11.0 & $(10.8,11.2)$ & 3.1 & $(3.0,3.2)$ \\
\hline \multirow{4}{*}{7} & Home & 615 & 4,929 & 11.9 & $(11.7,12.2)$ & 3.3 & $(3.2,3.4)$ \\
\hline & GP & 945 & 7,799 & 10.3 & $(10.2,10.5)$ & 2.3 & $(2.3,2.4)$ \\
\hline & Hospital & 485 & 3,760 & 11.1 & $(10.8,11.4)$ & 2.5 & $(2.3,2.7)$ \\
\hline & Total & 2,045 & 16,488 & 11.0 & $(10.9,11.1)$ & 2.7 & $(2.6,2.7)$ \\
\hline \multirow{4}{*}{ Total } & Home & 4,802 & 39,011 & 12.6 & $(12.5,12.7)$ & 3.8 & $(3.7,3.8)$ \\
\hline & GP & 18,120 & 146,761 & 10.8 & $(10.8,10.9)$ & 2.9 & $(2.8,2.9)$ \\
\hline & Hospital & 2,348 & 17,448 & 11.6 & $(11.5,11.8)$ & 3.0 & $(2.9,3.1)$ \\
\hline & Total & 25,270 & 203,220 & 11.2 & $(11.2,11.3)$ & 3.0 & $(3.0,3.1)$ \\
\hline
\end{tabular}

N.B. INR checks and warfarin dose changes (both square root) in Centre 1 had significantly the highest recorded number $(P<0.0001)$ whereas for other centres recordings were fairly similar. GP and home setting in Centre 1 had significantly greater number of INR checks and warfarin dose changes per patient per year in comparison to respective settings in the other centres $\left({ }^{*} \mathrm{P}<0.001\right)$. Hospital setting in Centre 6 carried out significantly higher number of INR checks and number of dose changes per patient per year compared to hospital settings in centres 2 and 7 $(\neq \mathrm{P}<0.01)$.

This article is protected by copyright. All rights reserved. 


\section{Figure Legends}

Figure 1: Percentage time spent (a) within target INR range, (b) above target range, and (c) below target range, for the whole study population with $95 \%$ confidence limits (dashed lines).

Figure 2: Square root of number of INR monitoring events (a) and square root of number of warfarin dose changes (b) for the whole study population with $95 \%$ confidence limits (dashed lines).

Figure 3: Percentage time spent (a) within target INR range, (b) above target range, and (c) below target range according to centre. (black=centre 1, red=centre 2 , green $=$ centre 3 , dark blue $=$ centre 4 , light blue $=$ centre 5 , purple $=$ centre 6 , yellow= centre 7) 

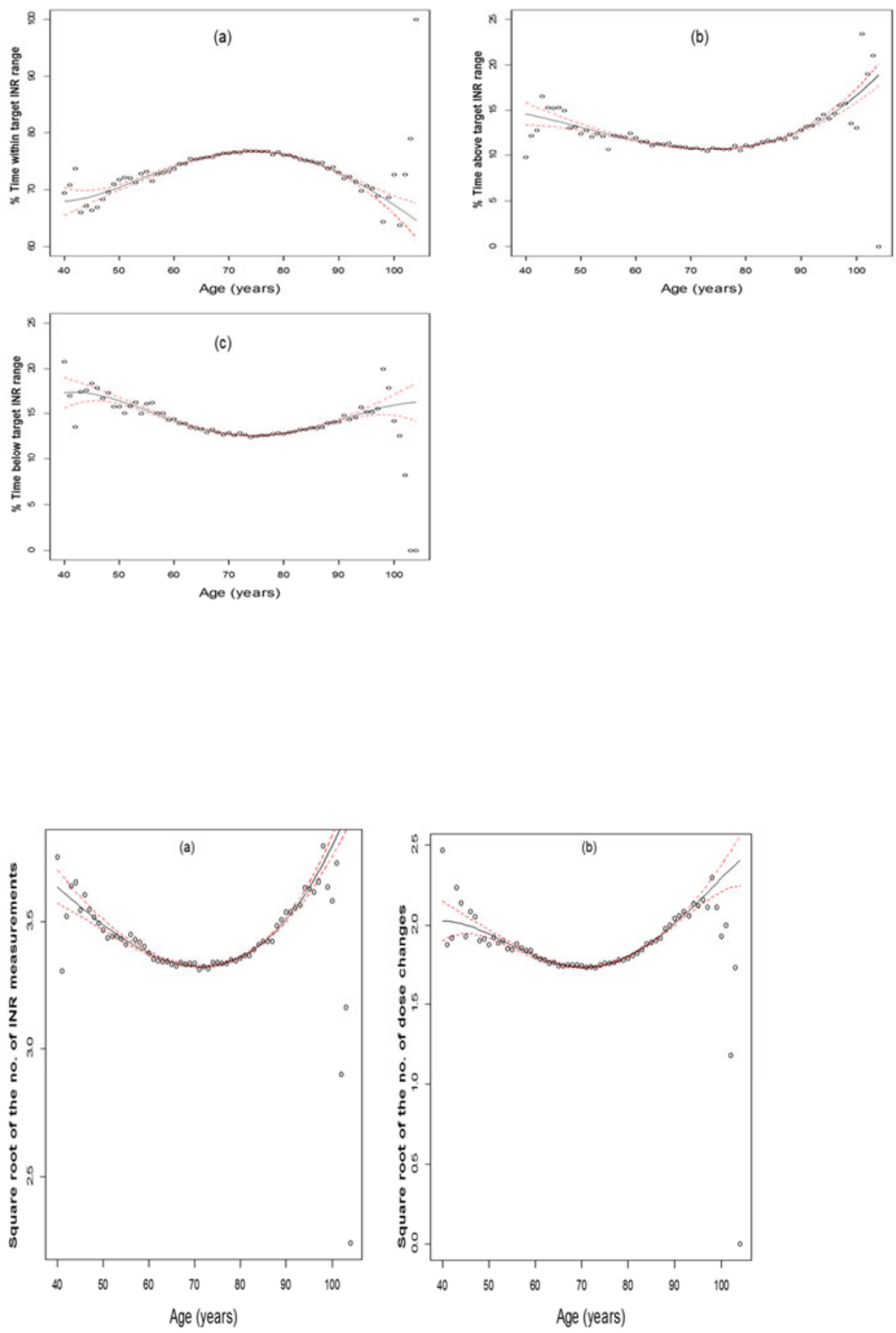

This article is protected by copyright. All rights reserved. 

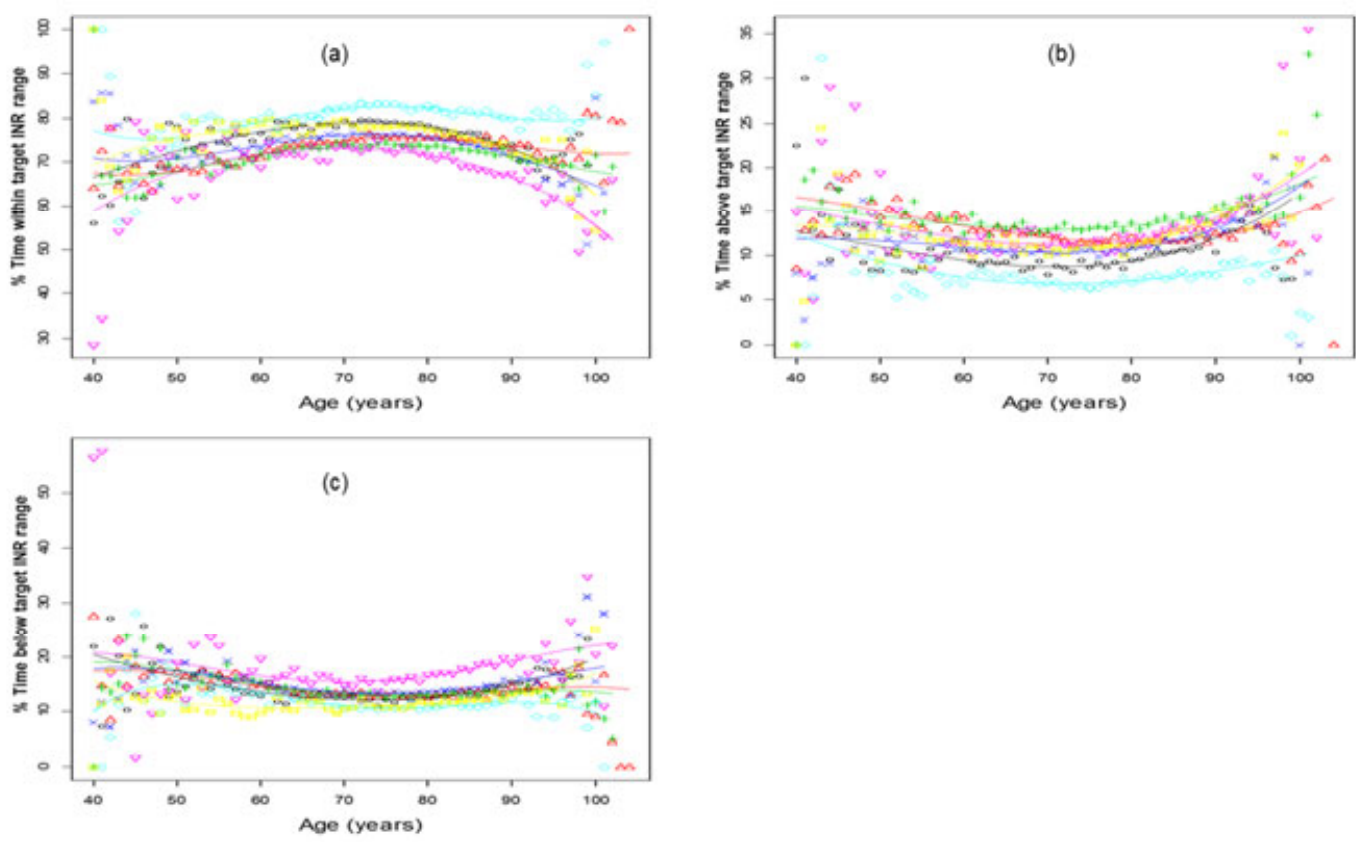

This article is protected by copyright. All rights reserved. 